\title{
Emotional State of Diabetics - A Gender Base Analysis
}

\author{
Parul Niranjan $^{1 *}$, Dr. Smita Jaiswal ${ }^{2}$
}

\section{ABSTRACT}

To compare the emotional state of male and female diabetics a sample of 200 diabetics (100 male and 100 female), age 35-55 years, was randomly selected from Jaloun (Uttar Pradesh) India. Eight state questionnaires were administered on these subjects. Critical Ratio was applied to study the significance of difference. Result of the study revealed significant difference between the emotional state of male and female diabetics.

\section{Keywords: Emotional State, Diabetics, Gender}

Being diagnosed with diabetes is a major life stress. (Lustman P. J., Griffith, L. S. freedl and, K.E. Clouse, R.E., (1997) ). It requires a large number of physical and mental accommodations. Each person has a somewhat different response to stress. When one experience stress body tends to respond as if were under attack. This can be regardless of whether the stress is physical or psychological. The body responds to stress by preparing itself to take action. This is called the "fight-or-flight" response. In the fight-or-flight response, the levels of many hormones rise. These hormones include adrenaline, growth hormone and glucocorticosteorides. These hormones have a role in creating negative emotional states.

Negative emotional state can have major implications for diabetes including-

- $\quad$ Increased blood glucose levels, and therefore a higher risks of long-term complications.

- $\quad$ Reduced social activity and quality of life.

- $\quad$ Decreased physical activity and increased likelihood of obesity

- $\quad$ Greater likelihood of smoking or alcohol abuse.

Review of literature revealed from some emotional problems in diabetics population.

Anderson R.J., Lustman P.J., Clouse R.E., et al. (2000) found that approximately 30\% of patients with diabetes (types 1and 2) experience comorbid depression. There is a significant association between depression and hyperglycaemia in type 1 and type 2 diabetes.

\footnotetext{
${ }^{1}$ Research scholar, D.V.C. Orai, Jaloun, Uttar Pradesh, India.

${ }^{2}$ Associate Professor, Department of Psychology, B.K.D. College, Jhansi, U.P., India.

*Responding Author

(C) 2016, P Niranjan, S Jaiswal; licensee IJIP. This is an Open Access Research distributed under the terms of the Creative Commons Attribution License (http://creativecommons.org/licenses/by/2.0), which permits unrestricted use, distribution, and reproduction in any Medium, provided the original work is properly cited.
} 


\section{Emotional State of Diabetics - A Gender Base Analysis}

Sachs G, Speiss K, Moser G. (1991) found that there is a direct correlation between severity of depressive symptoms, incidence of complaints of diabetes, and level of blood glucose in patients with type 1diabetes.

According to Gonzalez.et al. \& Sridhar, (2007) people with Diabetes were twice as likely to have depression compared to those without Diabetes and also found to have more complexities in management of Diabetes or to euro-hormonal abnormalities.

According to Grigsby A.B., Anderson R.J., Freedland K.E., Clouse R.E., Lustman P. J. (2002) the generalized anxiety disorder (GAD) was present in $14 \%$ of patients with diabetes. The subsyndromal presentation of anxiety disorder not otherwise specified and of elevated anxiety symptoms were found in $27 \%$ and $40 \%$, respectively, of patients with diabetes. The prevalence of elevated symptoms was significantly higher in women compared to men (55.3\% vs. $32.9 \%$, $\mathrm{P}<.0001$ ) and similar in patients with Type 1 vs. Type 2 diabetes (41.3\% vs. $42.2 \%, \mathrm{P}=.80$ ).

The Canadian Diabetes Association (1999) confirms that feelings of anxiety and depression are common among people with diabetes and can negatively affect blood glucose values and diabetes self-management, contributing to the risk of serious complications; consequently, people with diabetes may benefit from depression screening and treatment.

Rubin \& Peyrot, (2001) found that the magnitude of the daily work is daunting and has been associated with psychological fatigue, often called "diabetes burnout", which may lead to poor diabetes health outcomes.

Anderson et al. (2001) found that individuals with diabetes were twice as likely to have depression when compared to individuals in the same setting without diabetes.

Due to extensive psychological and physiological changes, the clinical management of disorder requires a lot of factors to be kept in consideration. There are very few studies who have explored the gender issue in diabetes.

According to Lloyd C.E., Dyer P.H., Barnett A.H. (2000),women are twice as likely as men to experience depression, men suffer because they are less likely than women to seek help. For men, its often masked by alcohol or drug abuse, which may seem more socially acceptable than seeking psychiatric help. In a study, men were more likely to report moderate to severe depression symptoms and women more moderate to severe anxiety symptoms.

Lawrence J. M., Standiford D. A., Loots B., (2005) found the prevalence of depressed mood to be higher among males with type 2 diabetes than those with type 1 diabetes and to be higher among females with co morbidities than those without co morbidities. 


\section{Emotional State of Diabetics - A Gender Base Analysis}

Lustman et al. (1977) reported that Women with diabetes suffer more from depression then men with diabetes. The changes of becoming depressed increase as diabetes complication worsen. A person with depression is less likely to follow medication or healthy eating plans.

Although above mentioned studies have shown evidence of emotional problems in diabetic population, very few studies have explored the gender issue. Review of the literature suggests extreme scarcity of studies on Indian samples. Present study explores the emotional states of diabetics and presents a comparative analysis of male and female.

\section{Aim}

1. To compare the emotional states of male and female diabetic.

\section{Hypothesis}

2. There is no significant difference between emotional states of male and female.

\section{Sample}

The total sample for the study consisted of randomly selected 200 subjects from the age range of 35-55 years and same middle socio-economic status. Out of 200 subjects there are 100 male (50 type- 1 and 50 type- 2 diabetics) and 100 female (50 type- 1 and 50 type-2 diabetics). All the subjects were contacted directly after taking telephonic appointment. All the subjects were clinically diagnosed by qualified physician and were under treatment from one year. The sample was taken from Jalaun (Uttar Pradesh) India.

\section{Tools}

Eight State Questionnaire (8SQ) developed by Malay Kapoor and Mahesh Bhargava (1989) was used to asses the basic component of emotional states (such as -anxiety, stress, depression, regression, fatigue, guilt, extraversion and arousal).

\section{Design}

Ex-post-facto research design.

\section{Statistical Analysis}

The obtained data were analysed by applying critical ratio to find out the significance of difference between the emotional state of male and female diabetics. 
Emotional State of Diabetics - A Gender Base Analysis

RESULT AND INTERPRETATION

Table-1, Mean, SD and CR Values between male and female Diabetics on emotional state

\begin{tabular}{|c|c|c|c|c|c|}
\hline \multirow[b]{2}{*}{8 SQ Factor } & \multicolumn{4}{|c|}{ Emotional State } & \multirow[b]{2}{*}{ CR } \\
\hline & \multicolumn{2}{|c|}{ Male } & \multicolumn{2}{|c|}{ Female } & \\
\hline \multirow{2}{*}{ ANXIETY } & Mean & 17.51 & Mean & 16.75 & 1.26 \\
\hline & SD & 4.54 & SD & 3.98 & NS \\
\hline \multirow{2}{*}{ STRESS } & Mean & 16.87 & Mean & 16.82 & 0.10 \\
\hline & SD & 3.51 & SD & 3.65 & NS \\
\hline \multirow{2}{*}{ DIPRESSION } & Mean & 17.68 & Mean & 17.59 & 0.18 \\
\hline & $\mathrm{SD}$ & 3.50 & SD & 3.49 & NS \\
\hline \multirow{2}{*}{ REGRESSION } & Mean & 17.42 & Mean & 17.85 & 0.73 \\
\hline & SD & 3.98 & SD & 4.32 & NS \\
\hline \multirow{2}{*}{ FATIGUE } & Mean & 17.20 & Mean & 17.96 & 1.04 \\
\hline & $\mathrm{SD}$ & 5.30 & SD & 5.01 & NS \\
\hline \multirow{2}{*}{ GUILT } & Mean & 15.42 & Mean & 16.01 & 0.88 \\
\hline & $\mathrm{SD}$ & 4.71 & SD & 4.78 & NS \\
\hline \multirow{2}{*}{ EXTRA VERSION } & Mean & 17.39 & Mean & 17.04 & 0.65 \\
\hline & SD & 3.98 & SD & 3.63 & NS \\
\hline \multirow{2}{*}{ AROUSAL } & Mean & 17.91 & Mean & 18.26 & 0.83 \\
\hline & SD & 2.63 & SD & 3.30 & NS \\
\hline
\end{tabular}

d.f $198-->\quad$.05-->1.97

Showing the mean value of Male \& Female diabitics on different dimentions of $8 \mathrm{SQ}$

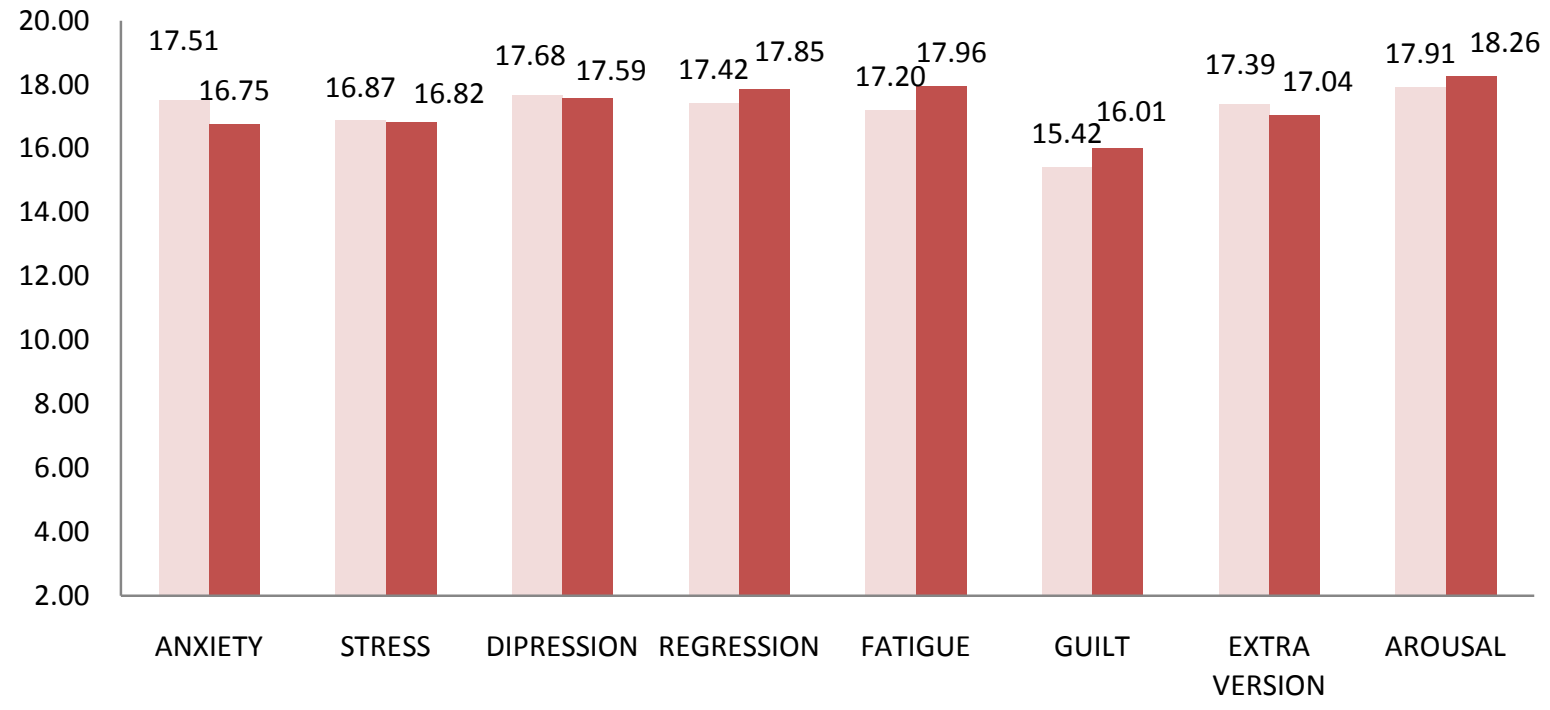




\section{Emotional State of Diabetics - A Gender Base Analysis}

Results revealed statistically no significant difference among all the emotional states i.e., anxiety $(C R=1.26)$, stress $(C R=0.10)$, depression $(C R=0.18)$, regression $(C R=0.73)$, fatigue $(C R=$ $1.04)$, guilt $(\mathrm{CR}=0.88)$, extraversion $(\mathrm{CR}=0.65)$ and arousal $(\mathrm{CR}=0.83)$.

Although male $(M=17.51, S D$ 4.54) were higher on anxiety than female $(M=16.75$, SD 3.98) but the difference was not statistically significant female were higher on arousal ( $M=18.26$, SD = 3.30) than male sample $(\mathrm{M}=17.91, \mathrm{SD}=2.63)$. The difference was not statistically significant. A large sample may reveal better results.

Result of present study are not consistent with the previous finding as reported by Lloyd et al. (2000), Lustman et al. (1977) and Lawrence et al. (2005) as they reported higher mood problems among females.

\section{CONCLUSION}

No significant difference was found in emotional state of type-1 and type-2 diabetics.

\section{Acknowledgments}

The author appreciates all those who participated in the study and helped to facilitate the research process.

\section{Conflict of Interests}

The author declared no conflict of interests.

\section{REFERENCES}

Anderson R. J., Lustman P. J., Clouse R. E., et al., (2000). Prevalence of depression in adults with diabetes: a systematic review (abstract). Diabetes Care 49: A64.

Anderson R. J., Freedland K. E., Clouse R. E., Lustman P. J., (2001). The prevalence of comorbid depression in adults with diabetes: a meta-analysis. Diabetes Care. 2001 Jun;24(6):1069-78.

Gonzalez J. S., Safren S. A., Cagliero E., Wexler D. J., Delahanty L., Wittenberg E., Blais M. A., Meigs J. B., Grant R. W. (2007). Depression, self-care, and medication adherence in type 2 Diabetes: relationships across the full range of symptom severity. Diabetes Care, Sep; 30(9):2222-7.

Grigsby A. B., Anderson R. J., Freedland K. E., Clouse R. E., Lustman P. J.(2002). Prevalence of anxiety in adults with diabetes: a systematic review. J Psychosom Res. 2002 Dec; 53 (6):1053-60.

Kapoor M. \& Bhargava M., (1989). Eight State Questionnaire (8SQ)

Lawrence J. M., Standiford D. A., Loots B., Klingensmith G. J.,(2005). Prevalence and Correlates of Depressed Mood Among Youth With Diabetes: The SEARCH for Diabetes in Youth Study ;American Academy of Pediatrics. 
Lloyd C. E., Dyer P. H., Barnett A. H., (2000). Prevalance of symptoms of depression and anxiety in a diabetes clinic population. Diabetic Medicine 17: 198-202.

Lustman P. J., Griffith, L. S., Freedl and, K. E., Clouse, R. E. et. al., (1997). Effects of Nortryptilie on depression and glycemic control in diabetes: Results of a double-lined, placebo controlled trial. Psychosomatic Medicine ; 59(3) 241-250.

Lustman P. J., Griffith, L. S., Freedl and, K. E., Clouse, R. E., (1997). The course of major Depression in Diabetics; Gen Hops Psychiatry ; 19(2) 138-143.

Rubin R. R., Peyrot M., (2001). Psychological issues and treatments for people with diabetes. $J$ Clin. Psychol. 57:457- 478.

Sachs G., Speiss K., Moser G., (1991). Glycosylated hemoglobin and Diabetes self-monitoring (compliance) in depressed and non-depressed type I diabetic patients. Psychother Pychosom Med Psychol 41: 306-312.

How to cite this article: P Niranjan, S Jaiswal (2016), Emotional State of Diabetics - A Gender Base Analysis, International Journal of Indian Psychology, Volume 3, Issue 4, No. 63, ISSN 2348-5396 (e), ISSN: 2349-3429 (p), DIP: 18.01.103/20160304, ISBN: 978-1-365-32518-2 